\title{
Narrowband Angular Reflectance Properties of the Alkali Flats at White Sands, New Mexico
}

\author{
Charles H. Whitlock, ${ }^{*}$ Stuart R. LeCroy ${ }^{\dagger}{ }^{\text {and Robert J. Wheeler }}{ }^{\dagger}$
}

\begin{abstract}
$R$ from helicopter measurements of the angular properties of surface reflectance for the alkali flats regions of the White Sands Missile Range are presented for the wavelength interval of 0.4 to $0.85 \mu \mathrm{m}$. This work was performed to allow accurate radiative transfer calculations over the region. Detailed tables and interpolation equations are given that permit other investigators to perform satellite calibrations over the alkali flats site. The effects of wavelength and soil moisture on narrowhand angular reflectance are also investigated. Although there is a spectral variation in surface albedo, there is little spectral effect in Anisotropic Factor except in the forwardscattering peak at solar zenith angles greater than $60^{\circ}$. The magnitude of the forward-scattering peak is also sensitive to soil moisture, with wet conditions causing a larger peak. The significance of this result is that angular reflectance properties at the center of the alkali flats usually will be different than those at the flats edge because moisture differences typically exist.
\end{abstract}

\section{INTRODUCTION}

Although satellite instruments are usually calibrated before flight, there is generally a need for recalibration once flight conditions have been achieved. These calibrations are often done using homogeneous, bright ground targets such as deserts. The ground-target approach (indirect method) employs a radiative transfer model to determine the upwelling directional radiance that reaches the satellite instrument's detector (Slater et al., 1987; Frouin and Gautier, 1987). This calculated

\footnotetext{
"Atmospheric Sciences Division, National Aeronautics and Space Administration. Langley Research Center, Lampton, VA

'Lockhered Enginecring and Sciences Company, Hampton, VA

Address correspondence to Charles H. Whitlock, Atmospheric Sciences Division, NASA Langley Research Center, MS. 420, Hampton, VA 73681 .

Rerried 17 December 1993; accepted 25 June 1994.

$0034-425 \% / 94 / \$ 700$

CHlsevier Science Inc., 1994

6.55 Acente of the Americas, New Fork, NY 10010
}

radiance is then compared to the digital instrument counts to determine the calibration coefficients. The success of this technique depends on how accurately both surface reflectance properties and atmospheric characteristics can be characterized. For bright targets, one key parameter is the angular distribution of surface reflectance (Jackson et al., 1990). This paper will only consider the surface reflectance as a function of solarzenith, view-zenith, and view-azimuth angles for the wavelength interval 0.4 to $0.85 \mu \mathrm{m}$.

Early satellite calibration studies (Frouin and Gautier, 1987) used laboratory-derived angular reflection properties, based on samples of White Sands Missile Range (WSMR) gypsum sand (Walraven and Coulson, 1972). Recent studies have shown that the angular reflectance properties of the WSMR dumes region are not the same as those of the WSMR alkali flats (Markham et al., 1990; Deering et al., 1990). Broadband (0.2-4.0 $\mu \mathrm{m})$ angular reflectance measurements of the alkali flats region have been made (Eaton and Dirmhirm, 1979), but narrowband measurements at the edge of the flats indicated the possibility of both spectral and surface texture effects (Deering et al., 1990).

From this history, it was deemed necessary to perform new narrowband angular reflectance measurements over the central part of the WSMR alkali flats region. This region was selected because it was a large, lowvegetated, semi-homogenous area suitable for use as a calibration target for operational satellites with pixel sizes up to $3 \mathrm{~km}$. This paper presents dedicated measurements that will permit other investigators to perform satellite calibrations over the alkali flats site.

\section{Measurement Technique}

Measurements of angular reflectance variability have been accomplished from a number of platforms, such as small towers or booms (Eaton and Dirmhirm, 1979; Deering and Leon, 1986; Jackson et al., 1990), fixedwing aircraft (Davis and Cox, 1982; Markham et al., 


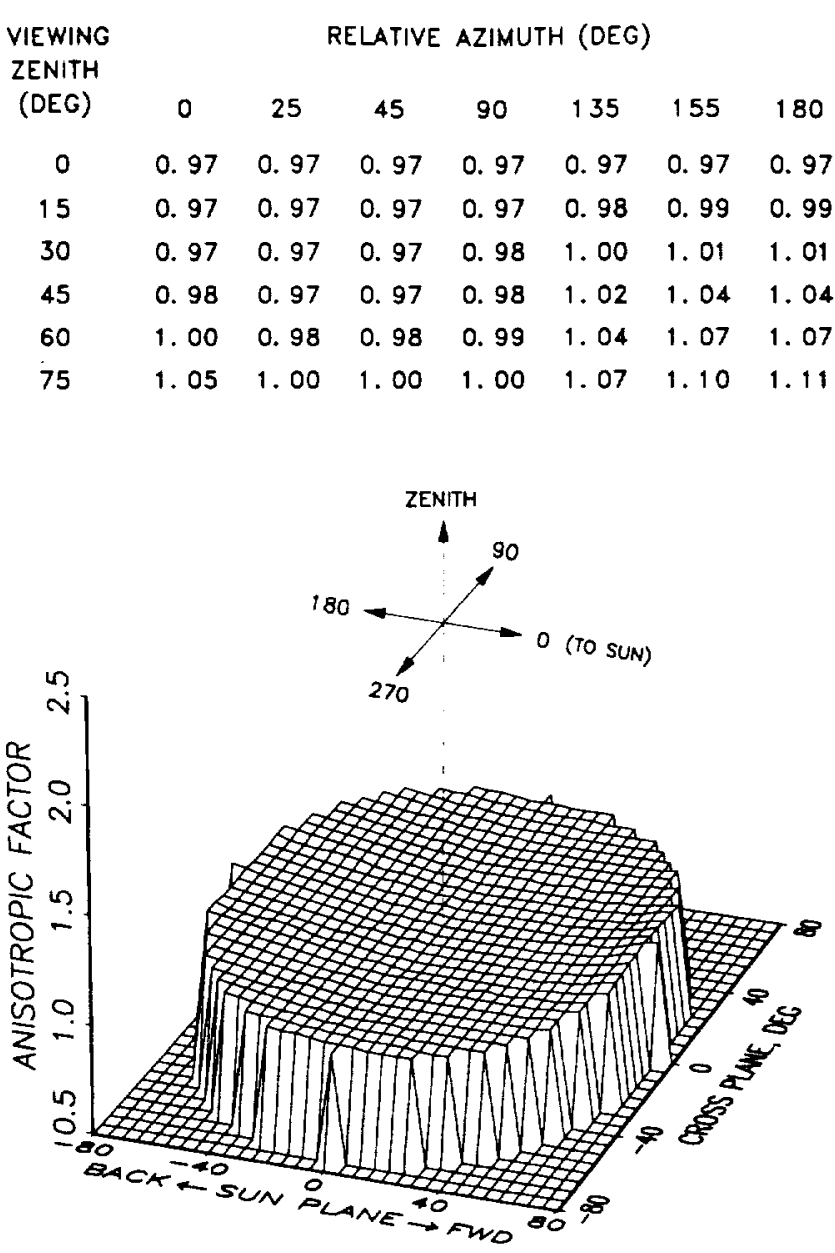

Figure 1. Bidirectional characteristics of WSMR at a wavelength of 0.65 micron and an albedo of 0.30 for a solarzenith angle of $15^{\circ}$.

1990; Irons et al., 1991), and helicopters (Whitlock et al., 1987; Williams et al., 1991; Purgold et al., 1994). The particular technique used depends on the target size, texture, and homogeneity combination; wavelength requirements; angular requirements; and level of sophistication of the radiative transfer model being used.

In our case, the initial requirement was for angular properties of surface reflectance for a $3 \times 3 \mathrm{~km}$ target near the center of the alkali flats at WSMR. The ultimate use of the data was in the Finite Difference Method radiative transfer model (Barkstrom, 1976; Suttles, 1981) to validate Advanced Very High Resolution Radiometer (AVHRR) and Visible Spin Scan Radiometer (VISSR) calibration coefficients. This model was selected for use because it considered all orders of scattering, has been intercompared with other radiative transfer methods (Suttles, 1985; Ellingson and Fouquart, 1990), and was verified with experimental data (Whitlock et al., 1985; 1990). The following angular reflectance cases were desired:

1. Solar zenith angles from $15^{\circ}$ to $80^{\circ}$.

2. View-zenith angles from $0^{\circ}$ to $75^{\circ}$.

$\begin{array}{cccccccc}\begin{array}{c}\text { VIEWING } \\ \begin{array}{c}\text { ZENITH } \\ \text { (DEG) }\end{array} \\ 0\end{array} & 0 & 25 & 45 & 90 & 135 & 155 & 180 \\ 0 & 0.92 & 0.92 & 0.92 & 0.92 & 0.92 & 0.92 & 0.92 \\ 15 & 0.92 & 0.91 & 0.91 & 0.93 & 0.96 & 0.96 & 0.96 \\ 30 & 0.92 & 0.91 & 0.92 & 0.94 & 1.00 & 1.02 & 1.03 \\ 45 & 0.95 & 0.92 & 0.93 & 0.96 & 1.06 & 1.10 & 1.11 \\ 60 & 1.00 & 0.95 & 0.95 & 0.98 & 1.12 & 1.17 & 1.19 \\ 75 & 1.14 & 1.01 & 0.99 & 1.01 & 1.19 & 1.26 & 1.29\end{array}$

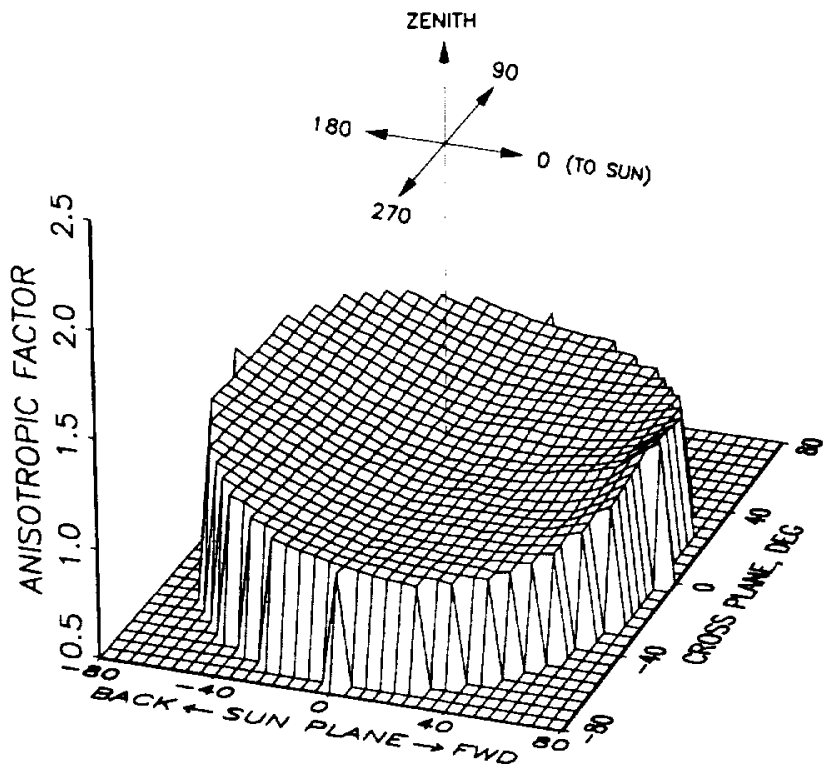

Higure 2. Bidirectional characteristics of WSMR at a wavelength of 0.65 micron and an albedo of 0.30 for a solarzenith angle of $40^{\circ}$.

3. View-azimuth angles from $0^{\circ}$ to $180^{\circ}$ relative to the plane of the sun. Symmetry is assumed about the plane of the sun.

4. Selected spectral bands between 0.40 and 0.85 $\mu \mathrm{m}$ with bandwidths less than $0.07 \mu \mathrm{m}$.

5. A range of soil moisture conditions.

The scanning-radiometer helicopter system described in Purgold et al. (1994) was used to perform the basic radiance measurements during May 1991. Simultaneous reflectance measurements were made at $0.4,0.55,0.65$, and $0.85 \mu \mathrm{m}$. Bandwidths were approximately $0.07 \mu \mathrm{m}$. The partial-cloverleaf flight pattern required 8 minutes to measure surface radiance from $0^{\circ}$ to $75^{\circ}$ in viewzenith angle at eight different view-azimuth angles relative to the solar plane. Patterns were flown for 33 different solar-zenith angles and two different soil moistures. The helicopter radiance data were integrated over angle to determine surface albedo, validated against surface albedo measurements (Wheeler et al., 1994), and comverted to Anisotropic Factors (AF) following Suttles et al. (1988). AF is defined as the ratio of $\Pi$ 


$\begin{array}{cccccccccc}\begin{array}{c}\text { VIEWING } \\ \begin{array}{c}\text { ZENITH } \\ \text { (DEG) }\end{array}\end{array} & 0 & 25 & 45 & 90 & 135 & 155 & 180 & \begin{array}{c}\text { RIEWING } \\ \text { ZENITH } \\ \text { (DEG) }\end{array} \\ 0 & 0.91 & 0.91 & 0.91 & 0.91 & 0.91 & 0.91 & 0.91 & 0 \\ 15 & 0.89 & 0.89 & 0.89 & 0.91 & 0.94 & 0.96 & 0.96 & 15 \\ 30 & 0.89 & 0.89 & 0.89 & 0.92 & 1.00 & 1.03 & 1.03 & 30 \\ 45 & 0.93 & 0.90 & 0.91 & 0.95 & 1.07 & 1.12 & 1.14 & 45 \\ 60 & 1.01 & 0.94 & 0.94 & 0.98 & 1.14 & 1.21 & 1.25 & 60 \\ 75 & 1.18 & 1.02 & 1.00 & 1.01 & 1.23 & 1.32 & 1.37 & 75\end{array}$

$\begin{array}{cccccccc}\begin{array}{c}\text { VIEWING } \\ \begin{array}{c}\text { ZENITH } \\ \text { (DEG) }\end{array} \\ \text { REG }\end{array} & 0 & 25 & 45 & 90 & 135 & 155 & 180 \\ 0 & 0.88 & 0.88 & 0.88 & 0.88 & 0.88 & 0.88 & 0.88 \\ 15 & 0.87 & 0.86 & 0.87 & 0.89 & 0.91 & 0.92 & 0.93 \\ 30 & 0.89 & 0.87 & 0.87 & 0.91 & 0.97 & 1.00 & 1.00 \\ 45 & 0.94 & 0.90 & 0.90 & 0.95 & 1.06 & 1.10 & 1.12 \\ 60 & 1.08 & 0.97 & 0.95 & 0.99 & 1.16 & 1.24 & 1.29 \\ 75 & 1.31 & 1.07 & 1.03 & 1.03 & 1.29 & 1.41 & 1.50\end{array}$

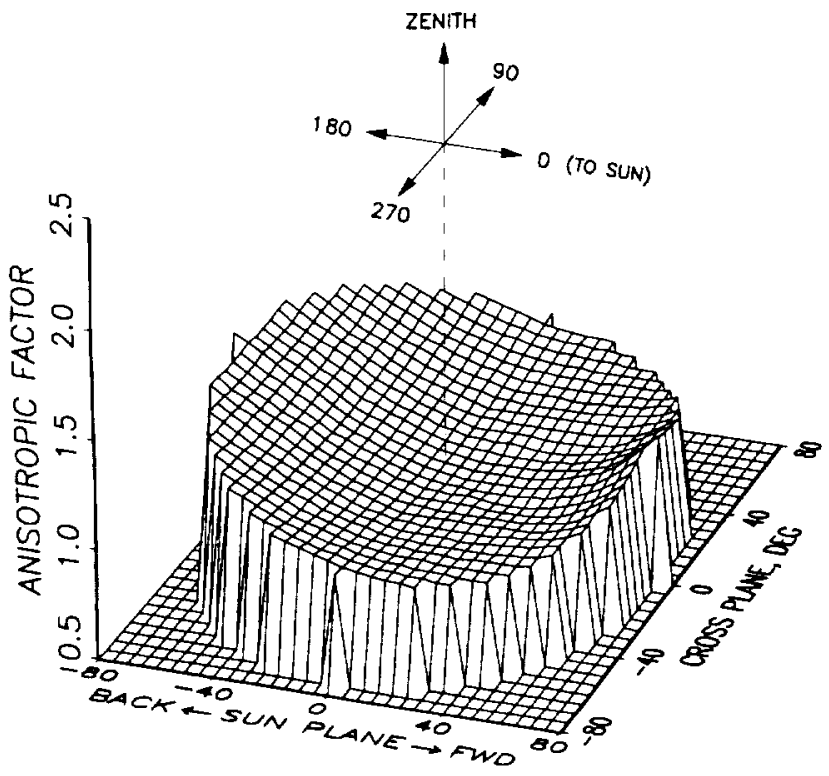

Figure 3. Bidirectional characteristics of WSMR at a wavelength of 0.65 micron and an albedo of 0.30 for a solarzenith angle of $50^{\circ}$.

times the directional radiance at a given view angle divided by the upward hemispherical irradiance from the surface. AF equals 1.0 at all angles for a Lambertian surface. Non-Lambertian AF values may be converted to relative bidirectional reflectance factor $(\mathrm{RBRF})$ values (Jackson et al., 1990) by dividing the AF value at an arbitrary view-zenith and view-azimuth angle by the $\mathrm{AF}$ value at nadir (view-zenith $=0$ ). AF values are validated following a concept analogous to that of Moran et al. (1990).

\section{RESULTS}

The relation between soil moisture and surface albedo is unknown in this region because standard moisture test procedures do not provide consistent results with the alkali flats material. Standard bake-out temperatures do not remove all water in the gypsum/salt/algae/ lichen soil mixtures. For this reason, we use surface albedo as an indicator of soil moisture variability in this report. Wheeler et al. (1994) indicate that surface albedo

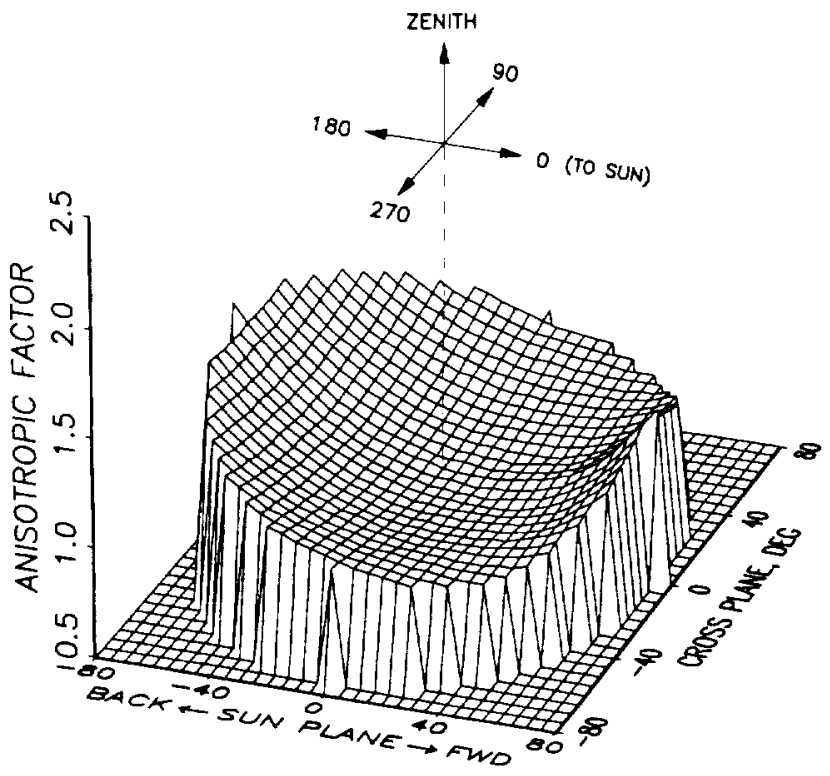

Figure 4. Bidirectional characteristics of WSMR at a wavelength of 0.65 micron and an albedo of 0.30 for a solarxenith angle of $60^{\circ}$.

values range from 0.22 (saturated with water) to 0.52 (unusually dry conditions) at a wavelength of $0.55 \mu \mathrm{m}$. Typical albedo values during the months of January, April, May, November, and December (when minimum cloud cover is observed) range from 0.30 to 0.45 with the variation on a daily basis depending on local rainfall. WSMR dune's albedos are higher but with a similar range of variability.

All surface albedo values are given for a wavelength of $0.55 \mu \mathrm{m}$ for the remainder of this report. This wavelength is used because inexpensive instrumentation is commercially available (LI-COR Model $210 \mathrm{SB}$ ) for monitoring albedo from 0.5 to $0.6 \mu \mathrm{m}$. Values at $0.40,0.65$, and $0.85 \mu \mathrm{m}$ wavelengths may be obtained by multiplying the $0.55 \mu \mathrm{m}$ value by the following correction factors:

Wavelength, $\lambda \quad 0.40 \mu \mathrm{m} \quad 0.55 \mu \mathrm{m} \quad 0.65 \mu \mathrm{m} \quad 0.85 \mu \mathrm{m}$ $\begin{array}{lllll}\text { Correction Factor } & 0.48 & 1.00 & 1.22 & 1.26\end{array}$

The above correction factors are the average of a number of albedo measurements at each of the four wave- 


$\begin{array}{cccccccc}\begin{array}{c}\text { VIEWING } \\ \begin{array}{c}\text { ZENITH } \\ \text { (DEG) }\end{array}\end{array} & 0 & 25 & 45 & 90 & 135 & 155 & 180 \\ 0 & 0.86 & 0.86 & 0.86 & 0.86 & 0.86 & 0.86 & 0.86 \\ 15 & 0.85 & 0.86 & 0.85 & 0.86 & 0.92 & 0.92 & 0.90 \\ 30 & 0.90 & 0.89 & 0.87 & 0.87 & 1.00 & 1.01 & 1.00 \\ 45 & 1.02 & 0.93 & 0.91 & 0.90 & 1.09 & 1.14 & 1.15 \\ 60 & 1.27 & 1.10 & 1.05 & 0.94 & 1.19 & 1.31 & 1.39 \\ 75 & 1.59 & 1.42 & 1.32 & 0.99 & 1.31 & 1.50 & 1.65\end{array}$

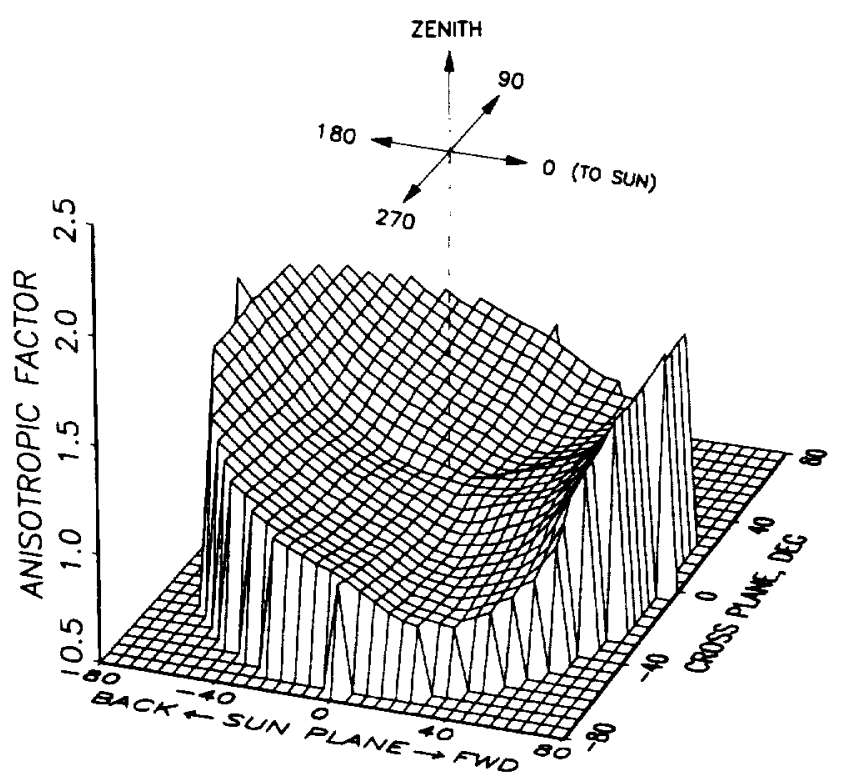

Figure 5. Bidirectional characteristics of WSMR at a wavelength of 0.65 micron and an albedo of 0.30 for a solarzenith angle of $70^{\circ}$.

lengths at two albedo values from the helicopter. Measurements at albedos of 0.30 and 0.42 indicate that moderate variations in soil moisture do not have a significant effect on spectral characteristics of surface albedo for the alkali flats.

For reasons of brevity, results have been synthesized to a common set of solar-zenith, view-zenith, and view-azimuth angles where straight-line interpolations may be used to represent the data. Figures 1 to 6 show $\mathrm{AF}$ results at $0.65 \mu \mathrm{m}$ for a surface albedo of 0.30 (at $0.55 \mu \mathrm{m}$ ) for six solar zenith angles. These data represent moderately damp soil-moisture conditions. Figures 7 to 12 show the same results for a surface albedo of 0.42 representing moderately dry conditions. Data for 0.65 $\mu \mathrm{m}$ were selected for display because that wavelength is most common to many different satellite instruments.

AF values for other wavelengths within the range of 0.40 to $0.85 \mu \mathrm{m}$ may be computed from:

$$
\mathrm{AF}_{\lambda}=\mathrm{AF}_{\lambda=0.65} *[1+(\lambda-0.65) * \mathrm{TAN} \beta]
$$

$\begin{array}{cccccccc}\begin{array}{c}\text { VIEWING } \\ \text { ZENITH } \\ \text { (DEG) }\end{array} & 0 & 25 & 45 & 90 & 135 & 155 & 180 \\ 0 & 0.83 & 0.83 & 0.83 & 0.83 & 0.83 & 0.83 & 0.83 \\ 15 & 0.85 & 0.85 & 0.84 & 0.83 & 0.88 & 0.88 & 0.86 \\ 30 & 0.99 & 0.97 & 0.93 & 0.84 & 0.95 & 0.97 & 0.96 \\ 45 & 1.20 & 1.11 & 1.04 & 0.86 & 1.04 & 1.09 & 1.11 \\ 60 & 1.54 & 1.37 & 1.26 & 0.91 & 1.14 & 1.25 & 1.35 \\ 75 & 2.02 & 1.81 & 1.63 & 0.97 & 1.25 & 1.43 & 1.63\end{array}$

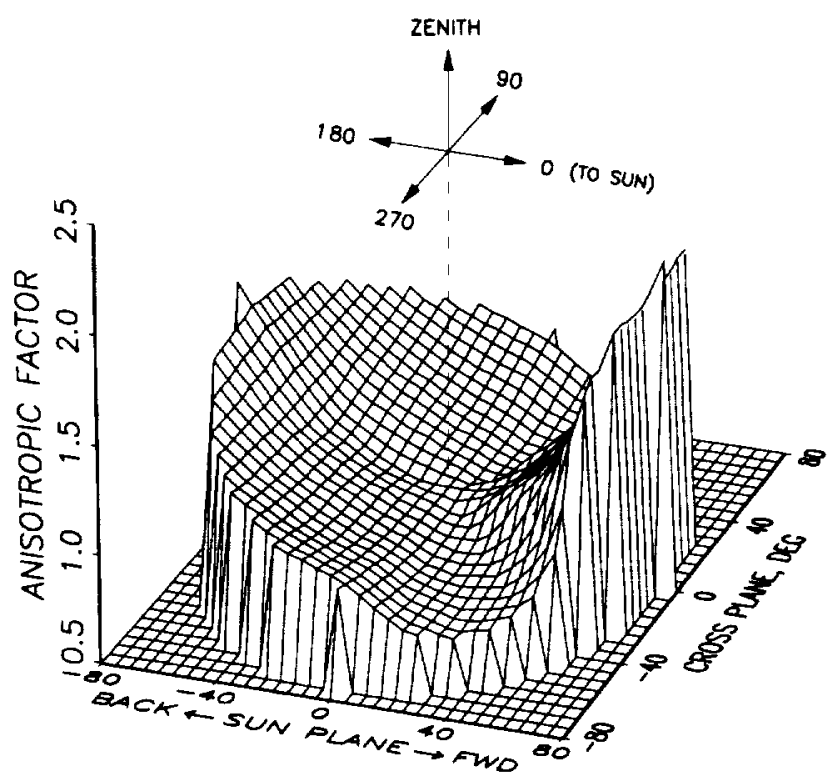

Figure 6. Bidirectional characteristics of WSMR at a wavelength of 0.65 micron and an albedo of 0.30 for a solarzenith angle of $80^{\circ}$.

where:

$\lambda=$ wavelength of interest in $\mu \mathrm{m}$.

$A F_{\lambda=0.65}=$ value from Figures 1 to 12 for the desired solar-zenith, view-zenith, view-azimuth, and surface albedo combination.

$\beta=$ value from Table 1 for the desired solar-zenith, view-zenith, view-azimuth, and surface albedo combination. $\beta$ is the slope of a least-squares-fit line on a plot of the $\mathrm{AF}_{\dot{\lambda}}$ to $\mathrm{AF} \lambda=0.65$ pratio as a function of $\lambda$.

In general, the relative accuracy of the calculated $\mathrm{AF}_{\lambda}$ is within $6 \%$ of the measured $\mathrm{AF}_{\lambda}$ for all solar-zenith, view-zenith, view-azimuth, and surface albedo combinations except portions of the forward-scattered peaks at the $70^{\circ}$ and $80^{\circ}$ solar-zenith angles. The following correction to equation (1) is required for those viewzenith and view-azimuth angles within the forwardscattered peak: 


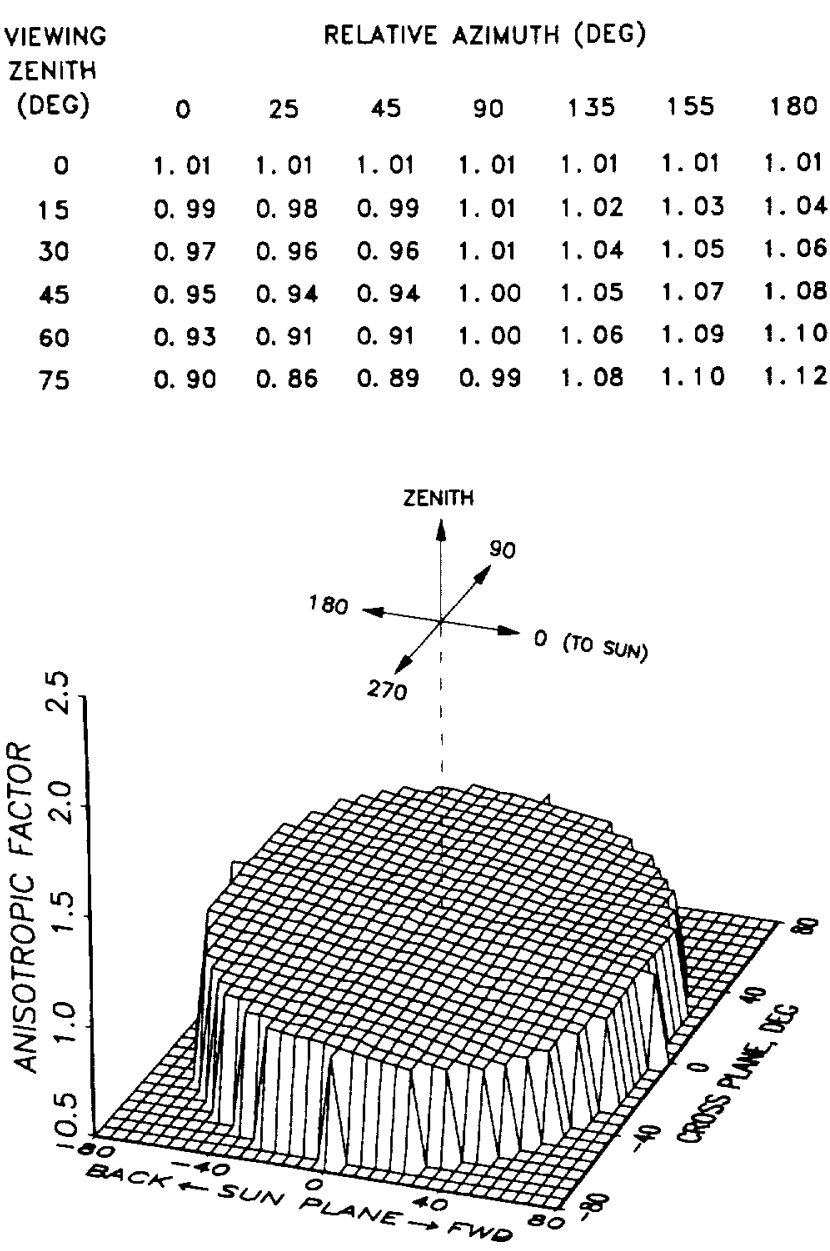

Figure 7 . Bidirectional characteristics of WSMR at a wavelength of 0.65 micron and an albedo of 0.42 for a solarzenith angle of $15^{\circ}$.

$$
\mathrm{AF}_{\lambda}=\varepsilon *\left[\mathrm{AF}_{\lambda, \mathrm{EQN}(1)}\right]
$$

where $\varepsilon$ is a correction factor given in Tables 2 and 3 for the angles within the forward-scattering peak.

It is necessary to adjust $\mathrm{AF}$ values to account for the variation in soil moisture. The authors use a linear interpolation/extrapolation process based on surface albedo values at $0.55 \mu \mathrm{m}$. The linear process is necessary because angular measurements were made at only two values of surface albedo. The adjustment to obtain $\mathrm{AF}$ values at surface albedo, $A$, is:

$$
A F_{A}=A F_{A=0.30}+\left[(A-0.30) *\left(A F_{0.42}-A F_{0.30}\right) / 0.12\right]
$$

As the soil becomes more saturated with water, specular reflections effects may alter $A F$ values in a nonlinear manner. Therefore, the authors do not recommend using the $\mathrm{AF}$ data in this report for surface albedos below 0.27 .

$\begin{array}{cccccccc}\begin{array}{c}\text { VIEWING } \\ \begin{array}{c}\text { ZENITH } \\ \text { (DEG) }\end{array}\end{array} & 0 & 25 & 45 & 90 & 135 & 155 & 180 \\ 0 & 0.99 & 0.99 & 0.99 & 0.99 & 0.99 & 0.99 & 0.99 \\ 15 & 0.95 & 0.95 & 0.95 & 0.99 & 1.01 & 1.03 & 1.03 \\ 30 & 0.93 & 0.92 & 0.92 & 0.99 & 1.05 & 1.07 & 1.08 \\ 45 & 0.90 & 0.88 & 0.89 & 0.99 & 1.08 & 1.12 & 1.14 \\ 60 & 0.88 & 0.86 & 0.86 & 0.99 & 1.12 & 1.17 & 1.21 \\ 75 & 0.87 & 0.83 & 0.83 & 1.00 & 1.16 & 1.23 & 1.28\end{array}$

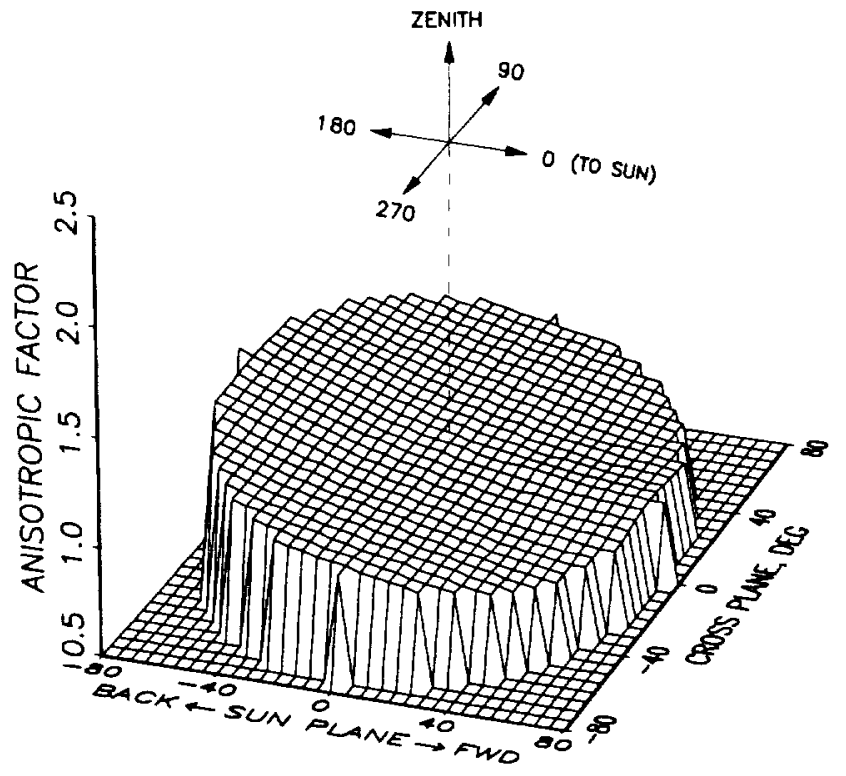

Figure 8. Bidirectional characteristics of WSMR at a wavelength of 0.65 micron and an albedo of 0.42 for a solarzenith angle of $40^{\circ}$.

\section{Validation}

The above helicopter-derived results may be verified in a limited manner by using satellite data from different view angles similar to Moran et al. (1990). Satellite digital counts should be approximately proportional to the radiance from the surface in the direction of the satellite if the atmospheric variation is not large and satellite calibration does not vary by a large amount. Directional radiance at the surface is proportional to scaled directional reflectance, which is the surface albedo times AF scaled by the cosine of the solar-zenith angle (SZA). Figure 13 shows NOAA-11 band-1 counts as a function of surface scaled directional reflectance calculated from surface-site albedo data (Wheeler et al., 1994) and helicopter AF values for a 31-month period beginning November 1988.

Satellite counts varied by a factor of two, depending 
VIEWING

ZENITH

(DEG)

0
15
30
45
60
75

RELATIVE AZIMUTH (DEG)

$\begin{array}{ccc}0 & 25 & 45 \\ 0.98 & 0.98 & 0.98 \\ 0.93 & 0.94 & 0.94 \\ 0.90 & 0.89 & 0.90 \\ 0.87 & 0.86 & 0.86 \\ 0.84 & 0.82 & 0.83 \\ 0.82 & 0.80 & 0.80\end{array}$

$90 \quad 135 \quad 155 \quad 180$

0.98

0.98

0.98

$\begin{array}{lllll}0.99 & 1.11 & 1.16 & 1.18\end{array}$

$\begin{array}{lllll}1.00 & 1.17 & 1.23 & 1.26\end{array}$

1.01

$1.23 \quad 1.31 \quad 1.35$

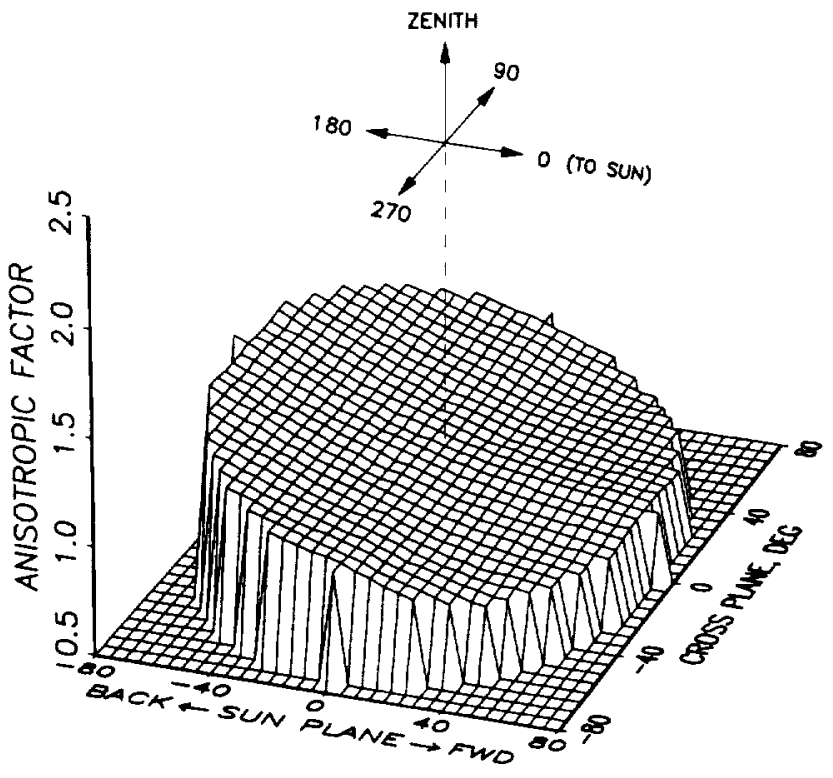

Figure 9. Bidirectional characteristics of WSMR at a wavelength of 0.65 micron and an albedo of 0.42 for a solarzenith angle of $50^{\circ}$.

mostly on a wide range of combinations of surface albedo, solar zenith angle, and AF, which existed during the period. Surface albedo ranged from 0.27 to 0.51 , and the solar-zenith angle varied from $18^{\circ}$ to $61^{\circ}$. View-zenith and view-azimuth angles ranged from $1^{\circ}$ to $41^{\circ}$ and $2^{\circ}$ to $171^{\circ}$, respectively. The solar-zenith, view-zenith, and view-azimuth combinations caused the AF to range from 0.89 to 1.07 , with a $20 \%$ variation.

Aerosol optical depth varied between 0.012 and 0.132 (LeCroy et al., 1994), and water vapor ranged from 0.1 to $0.8 \mathrm{~cm}$ from surface-site data. Radiative transfer calculations with these inputs (assuming Continental aerosols) indicate only $5 \%$ change in top-ofatmosphere radiance (or satellite counts). This uncertainty would show up as random scatter about the regression line in Figure 13.

Che and Price (1992) suggest that AVHRR band 1 may have slowly degraded as much as $3.5 \%$ per year (with absolute uncertainty equal to $7 \%$ ). More recent results (Rao and Chen, 1993) indicate a $1.2 \%$ per year

$\begin{array}{cccccccc}\begin{array}{c}\text { VIEWING } \\ \text { ZENITH } \\ \text { (DEG) }\end{array} & 0 & 25 & 45 & 90 & 135 & 155 & 180 \\ 0 & 0.93 & 0.93 & 0.93 & 0.93 & 0.93 & 0.93 & 0.93 \\ 15 & 0.88 & 0.88 & 0.89 & 0.94 & 0.98 & 0.99 & 1.00 \\ 30 & 0.87 & 0.87 & 0.87 & 0.95 & 1.03 & 1.07 & 1.09 \\ 45 & 0.90 & 0.90 & 0.89 & 0.96 & 1.10 & 1.15 & 1.18 \\ 60 & 0.96 & 0.94 & 0.92 & 0.99 & 1.18 & 1.26 & 1.29 \\ 75 & 1.02 & 1.00 & 0.98 & 1.01 & 1.28 & 1.38 & 1.42\end{array}$

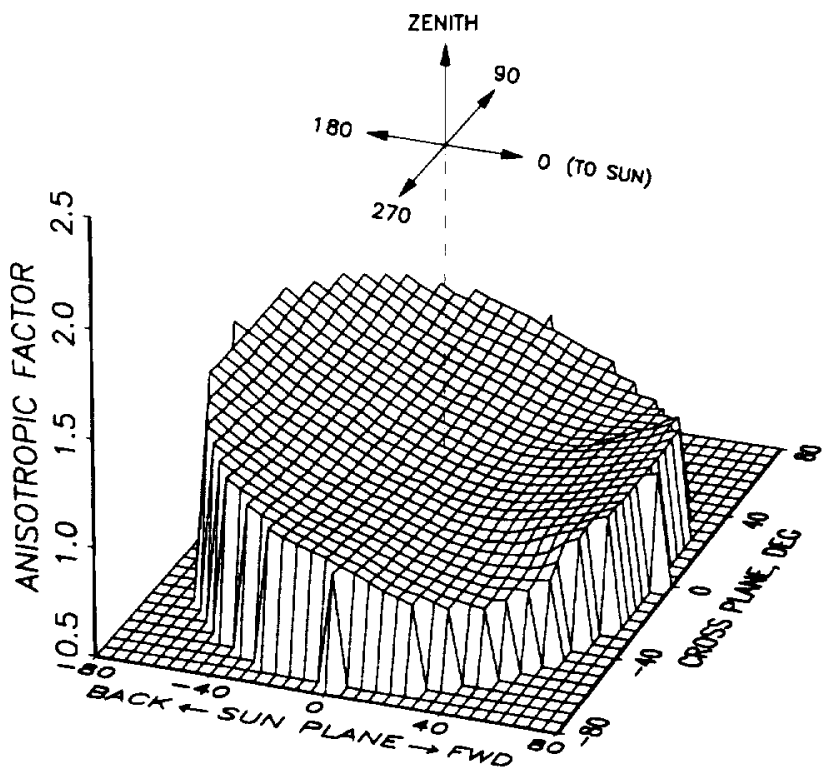

Figure 10. Bidirectional characteristics of WSMR at a wavelength of 0.65 micron and an albedo of 0.42 for a solarzenith angle of $60^{\circ}$.

degradation rate. Analysis of the 32 cases plotted in Figure 13 does not indicate a large degradation trend. Points separated by a 30-month time difference fall within $3 \%$ of each other for similar values of scaled directional reflectance. Random scatter caused by aerosol and water vapor variation may be partially hiding calibration degradation, however.

The scatter of the maximum counts about the regression line in Figure 13 is $6.1 \%$ (rms error equals $3.3 \%)$. Because this is similar to the atmospheric and calibration uncertainty, measurement errors for both surface albedo and $\mathrm{AF}$ are probably less than $6 \%$. There is no indication that either high or low values of $\mathrm{AF}$ cause counts to be either above or below the line for the 32 overflights in this experiment. Likewise, there is no evidence that the linear interpolation/ extrapolation process for soil moisture effects [Equation (3)] is not adequate for the albedo range of these overflights. Pairs of points at both ends of the albedo range $(0.27$ to 0.51$)$ fall very close to the line at similar values of scaled 


VIEWING
ZENITH
(DEG)
0
15
30
45
60
75

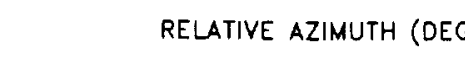

$\begin{array}{ccccccc}0 & 25 & 45 & 90 & 135 & 155 & 180 \\ 0.86 & 0.86 & 0.86 & 0.86 & 0.86 & 0.86 & 0.86 \\ 0.82 & 0.81 & 0.82 & 0.87 & 0.90 & 0.92 & 0.93 \\ 0.86 & 0.85 & 0.84 & 0.89 & 0.97 & 1.02 & 1.04 \\ 0.98 & 0.97 & 0.94 & 0.92 & 1.06 & 1.12 & 1.15 \\ 1.17 & 1.14 & 1.09 & 0.96 & 1.17 & 1.26 & 1.31 \\ 1.39 & 1.35 & 1.28 & 1.00 & 1.32 & 1.45 & 1.53\end{array}$

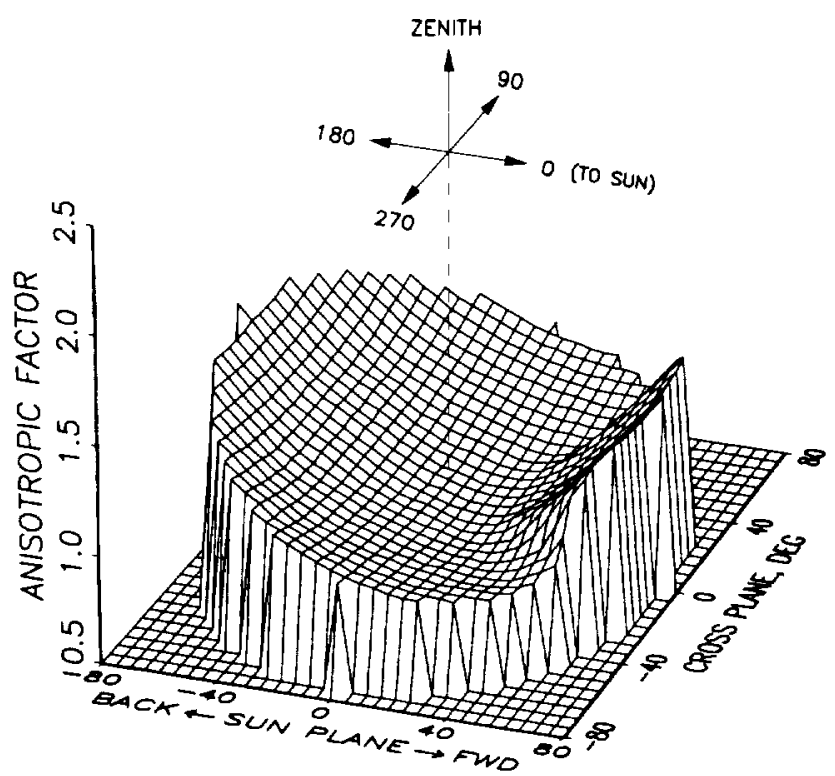

Figure 11. Bidirectional characteristics of WSMR at a wavelength of 0.65 micron and an albedo of 0.42 for a solarzenith angle of $70^{\circ}$.

directional reflectance. Results from this analysis give increased confidence in both the helicopter-measured $\mathrm{AF}$ values and the linear correction for soil moisture effects.

It should be noted that a significant change in aerosol type or magnitude can alter the validity of the above test. The data shown in Figure 3 are for the usual aerosol conditions at WSMR prior to arrival of the Mt. Pinatubo volcanic plume. Satellite counts taken within 6 months after the volcanic cloud reached WSMR were as much as $15 \%$ lower than would be expected, and the slope of the regression line was different than that in Figure 13. At some times during the post-Pinatubo period, volcanic-cloud optical depths in the stratosphere were five times that typical of the lower-altitude aerosol column. Knowledge of aerosol optical depth magnitudes and aerosol type is required to assess uncertainties caused by aerosols in the analysis.

$\begin{array}{cccccccc}\begin{array}{c}\text { VIEWING } \\ \begin{array}{c}\text { ZENITH } \\ \text { (DEG) }\end{array}\end{array} & 0 & 25 & 45 & 90 & 135 & 155 & 180 \\ 0 & 0.83 & 0.83 & 0.83 & 0.83 & 0.83 & 0.83 & 0.83 \\ 15 & 0.83 & 0.83 & 0.82 & 0.84 & 0.88 & 0.89 & 0.90 \\ 30 & 0.97 & 0.96 & 0.92 & 0.85 & 0.95 & 0.99 & 1.01 \\ 45 & 1.18 & 1.16 & 1.08 & 0.89 & 1.02 & 1.08 & 1.12 \\ 60 & 1.46 & 1.42 & 1.30 & 0.93 & 1.12 & 1.21 & 1.29 \\ 75 & 1.82 & 1.77 & 1.61 & 0.98 & 1.25 & 1.37 & 1.52\end{array}$

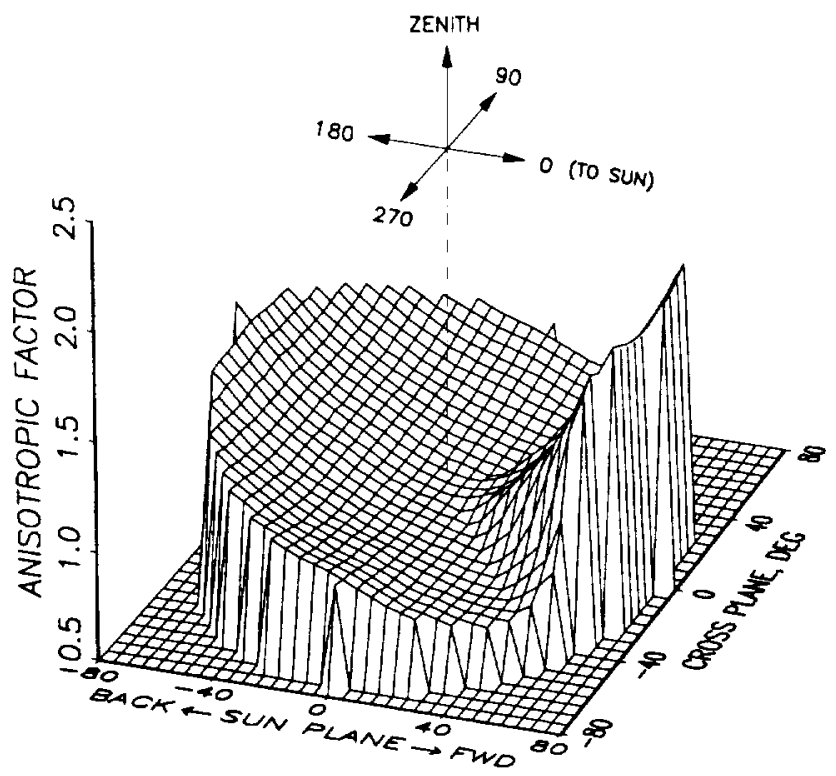

Figure 12. Bidirectional characteristics of WSMR at a wavelength of 0.65 micron and an albedo of 0.42 for a solarzenith angle of $70^{\circ}$.

\section{ANALYSIS}

It is of interest to assess both spectral and soil moisture effects on the angular reflectance properties of the alkali flats. For ease of comparison, we convert AF into RBRF in the plane of the Sun using the procedure discussed previously. Figures 14 and 15 show RBRF values for a SZA of $60^{\circ}$ at the two albedo values for which helicopter measurements were made. In both cases, the major wavelength effect appears to be in the peak in the forward-scattering direction. The cause of this characteristic has not been established. Table 1 shows low values of $\beta$ at low values of SZA indicating that wavelength effects become smaller as the $\mathrm{AF}$ forward-scattering peak is reduced in size.

Soil moisture effects are examined at two locations on the alkali flats region. As noted earlier, the helicopter measurements were conducted over a $3 \times 3 \mathrm{~km}$ central flats test area (CFTA) in May 1991. On November 16, 
Table 1. Beta Angles for Anisotropic Factor Spectral Correction

\begin{tabular}{|c|c|c|c|c|c|}
\hline \multirow{2}{*}{$\begin{array}{l}\text { Solar } \\
\text { zenith }\end{array}$} & \multirow{2}{*}{$\begin{array}{c}\text { View } \\
\text { zenith }\end{array}$} & \multicolumn{2}{|c|}{ View azimuth $(0-45)$} & $\begin{array}{c}\text { View } \\
\text { azimuth } \\
(90)\end{array}$ & \multirow{2}{*}{$\begin{array}{c}\text { View } \\
\text { azimuth } \\
(135-180) \\
\text { lbedos }\end{array}$} \\
\hline & & Albedo $=0.42$ & Albedo $=0.30$ & Both & \\
\hline \multirow[t]{6}{*}{15} & 0 & 1 & 2 & 2 & 2 \\
\hline & 15 & 1 & 1 & 1 & 2 \\
\hline & 30 & 1 & 0 & 1 & 2 \\
\hline & 45 & 1 & -1 & 0 & 1 \\
\hline & 60 & 0 & -3 & -1 & 0 \\
\hline & 75 & -1 & -6 & -1 & $-\mathbf{I}$ \\
\hline \multirow{6}{*}{40} & 0 & 3 & 6 & 4 & 5 \\
\hline & 15 & 2 & 3 & 4 & 5 \\
\hline & 30 & 1 & 0 & 3 & 4 \\
\hline & 45 & -1 & -3 & 1 & 2 \\
\hline & 60 & -2 & -9 & -1 & -1 \\
\hline & 75 & -4 & -15 & -3 & -3 \\
\hline \multirow[t]{6}{*}{50} & 0 & 3 & 7 & 5 & 6 \\
\hline & 15 & 3 & 4 & 5 & 6 \\
\hline & 30 & 2 & 0 & 4 & 5 \\
\hline & 45 & -2 & -3 & 3 & 3 \\
\hline & 60 & -6 & -10 & 1 & 0 \\
\hline & 75 & -11 & -18 & -5 & -1 \\
\hline \multirow[t]{6}{*}{60} & 0 & 5 & 5 & 5 & 5 \\
\hline & 15 & 0 & 5 & 4 & 6 \\
\hline & 30 & -5 & 2 & 3 & 7 \\
\hline & 45 & -9 & -5 & 1 & 6 \\
\hline & 60 & -12 & -19 & 0 & 5 \\
\hline & 75 & -15 & -21 & -1 & 4 \\
\hline \multirow[t]{6}{*}{70} & 0 & 4 & 10 & 6 & 10 \\
\hline & 15 & -4 & 5 & 7 & 10 \\
\hline & 30 & -16 & -1 & 6 & 11 \\
\hline & 45 & -17 & -17 & 4 & 12 \\
\hline & 60 & -16 & -32 & 2 & 11 \\
\hline & 75 & -12 & -39 & -1 & 10 \\
\hline \multirow[t]{6}{*}{80} & 0 & 6 & 10 & 9 & 9 \\
\hline & 15 & -6 & 2 & 8 & 13 \\
\hline & 30 & -18 & -7 & 7 & 16 \\
\hline & 45 & -31 & -31 & 6 & 17 \\
\hline & 60 & -35 & -48 & 3 & 19 \\
\hline & 75 & -30 & -47 & 2 & 20 \\
\hline
\end{tabular}

All values are in degrees, and $0^{\circ}$ azimuth is toward the Sun in the solar plane.

Figure 13. NOAA-11 band-1 counts versus scaled directional reflectance of surface.

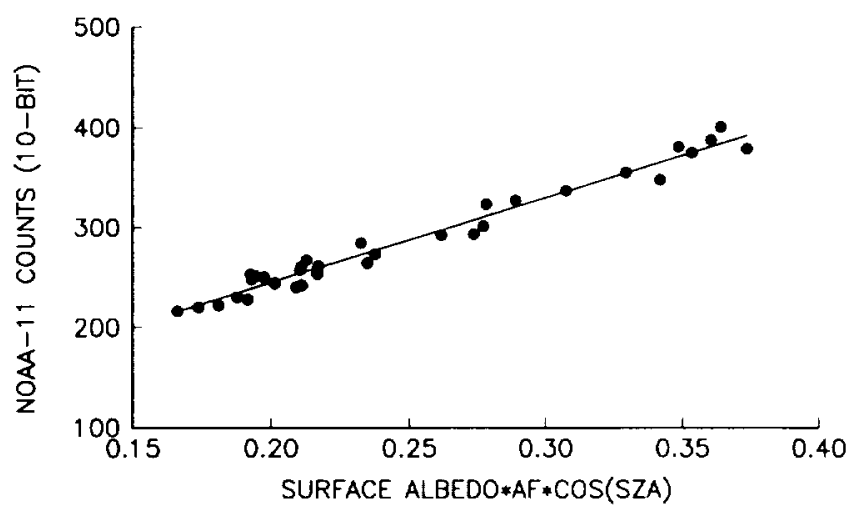

Figure 14. Relative Bidirectional Reflectance Function for albedo of 0.30 and solar-zenith angle of $60^{\circ}$.

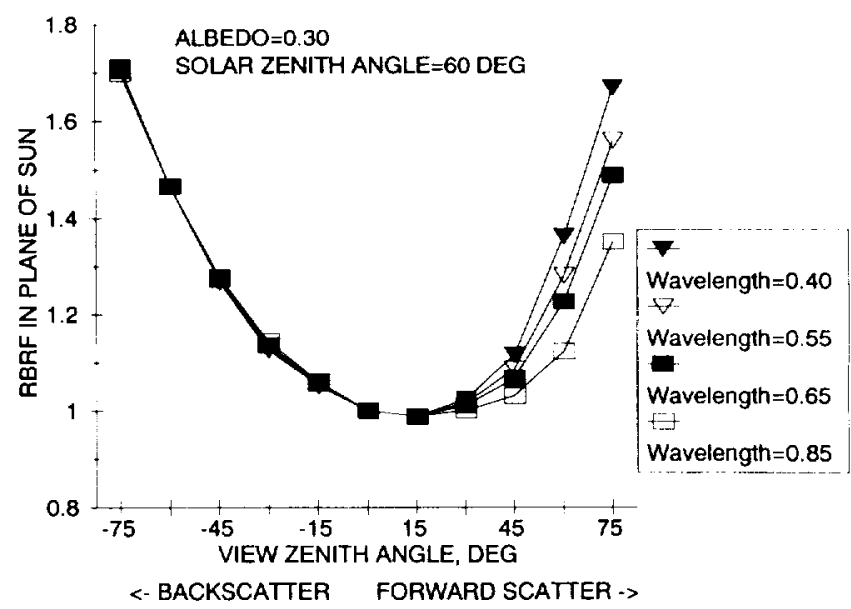


Table 2. Epsilon Correction Factor for Forward-Scattered Peak for Surface Albedo $=0.30$

\begin{tabular}{|c|c|c|c|c|c|}
\hline $\begin{array}{l}\text { Solar } \\
\text { zenith }\end{array}$ & $\begin{array}{c}\text { View } \\
\text { azimuth }\end{array}$ & $\begin{array}{c}\text { View } \\
\text { zenith }\end{array}$ & $\lambda=0.4 \mu \mathrm{m}$ & $\lambda=0.55 \mu \mathrm{m}$ & $\lambda=0.85 \mu \mathrm{m}$ \\
\hline \multirow[t]{4}{*}{$70^{\circ}$} & $0^{\circ}$ & $30^{\circ}$ & 0.98 & 1.00 & 0.99 \\
\hline & & $45^{\circ}$ & 0.94 & 0.99 & 0.95 \\
\hline & & $60^{\circ}$ & 0.90 & 1.00 & 0.91 \\
\hline & & $75^{\circ}$ & 0.83 & 0.98 & 0.93 \\
\hline \multirow[t]{4}{*}{$70^{\circ}$} & $25^{\circ}$ & $30^{\circ}$ & 0.99 & 0.99 & 0.99 \\
\hline & & $45^{\circ}$ & 1.03 & 0.99 & 0.99 \\
\hline & & $60^{\circ}$ & 0.98 & 0.93 & 0.92 \\
\hline & & $75^{\circ}$ & 0.91 & 0.95 & 0.84 \\
\hline \multirow[t]{4}{*}{$70^{\circ}$} & $45^{\circ}$ & $30^{\circ}$ & 1.00 & 1.00 & 1.00 \\
\hline & & $45^{\circ}$ & 1.02 & 0.99 & 1.01 \\
\hline & & $60^{\circ}$ & 0.97 & 0.93 & 0.96 \\
\hline & & $75^{\circ}$ & 0.92 & 0.95 & 0.89 \\
\hline \multirow[t]{4}{*}{$80^{\circ}$} & $0^{\circ}$ & $30^{\circ}$ & 0.93 & 0.96 & 0.92 \\
\hline & & $45^{\circ}$ & 0.88 & 0.92 & 0.87 \\
\hline & & $60^{\circ}$ & 0.80 & 0.89 & 0.84 \\
\hline & & $75^{\circ}$ & 0.75 & 0.85 & 0.81 \\
\hline \multirow[t]{4}{*}{$80^{\circ}$} & $25^{\circ}$ & $30^{\circ}$ & 0.93 & 0.95 & 0.91 \\
\hline & & $45^{\circ}$ & 0.93 & 0.92 & 0.90 \\
\hline & & $60^{\circ}$ & 0.84 & 0.84 & 0.84 \\
\hline & & $75^{\circ}$ & 0.78 & 0.83 & 0.74 \\
\hline \multirow[t]{4}{*}{$80^{\circ}$} & $45^{\circ}$ & $30^{\circ}$ & 0.94 & 0.96 & 0.95 \\
\hline & & $45^{\circ}$ & 0.92 & 0.92 & 0.94 \\
\hline & & $60^{\circ}$ & 0.85 & 0.85 & 0.89 \\
\hline & & $75^{\circ}$ & 0.80 & 0.83 & 0.78 \\
\hline
\end{tabular}

Table 3. Epsilon Correction Factor for Forward-Scattered Peak for Surface Albedo $=0.42$

\begin{tabular}{|c|c|c|c|c|c|}
\hline $\begin{array}{l}\text { Solar } \\
\text { zenith }\end{array}$ & $\begin{array}{c}\text { View } \\
\text { azimuth }\end{array}$ & $\begin{array}{l}\text { View } \\
\text { zenith }\end{array}$ & $\lambda=0.4 \mu \mathrm{m}$ & $\lambda=0.55 \mu \mathrm{m}$ & $\lambda=0.85 \mu \mathrm{m}$ \\
\hline \multirow[t]{4}{*}{$70^{\circ}$} & $0^{\circ}$ & $30^{\circ}$ & 1.03 & 0.97 & 1.01 \\
\hline & & $45^{\circ}$ & 1.01 & 0.93 & 0.97 \\
\hline & & $60^{\circ}$ & 1.00 & 0.91 & 0.95 \\
\hline & & $75^{\circ}$ & 0.99 & 0.89 & 0.93 \\
\hline \multirow[t]{4}{*}{$70^{\circ}$} & $25^{\circ}$ & $30^{\circ}$ & 1.03 & 0.97 & 1.01 \\
\hline & & $45^{\circ}$ & 1.01 & 0.93 & 0.97 \\
\hline & & $60^{\circ}$ & 1.00 & 0.91 & 0.95 \\
\hline & & $75^{\circ}$ & 0.99 & 0.89 & 0.93 \\
\hline \multirow[t]{4}{*}{$70^{\circ}$} & $45^{\circ}$ & $30^{\circ}$ & 1.01 & 0.98 & 1.02 \\
\hline & & $45^{\circ}$ & 1.01 & 0.94 & 0.99 \\
\hline & & $60^{\circ}$ & 1.00 & 0.92 & 0.97 \\
\hline & & $75^{\circ}$ & 1.00 & 0.90 & 0.94 \\
\hline \multirow[t]{4}{*}{$80^{\circ}$} & $0^{\circ}$ & $30^{\circ}$ & 0.95 & 0.93 & 0.92 \\
\hline & & $45^{\circ}$ & 0.92 & 0.88 & 0.87 \\
\hline & & $60^{\circ}$ & 0.87 & 0.83 & 0.82 \\
\hline & & $75^{\circ}$ & 0.83 & 0.77 & 0.76 \\
\hline \multirow[t]{4}{*}{$80^{\circ}$} & $25^{\circ}$ & $30^{\circ}$ & 0.95 & 0.93 & 0.92 \\
\hline & & $45^{\circ}$ & 0.92 & 0.88 & 0.87 \\
\hline & & $60^{\circ}$ & 0.87 & 0.82 & 0.82 \\
\hline & & $75^{\circ}$ & 0.83 & 0.77 & 0.76 \\
\hline \multirow[t]{4}{*}{$80^{\circ}$} & $45^{\circ}$ & $30^{\circ}$ & 0.95 & 0.94 & 0.96 \\
\hline & & $45^{\circ}$ & 0.92 & 0.89 & 0.91 \\
\hline & & $60^{\circ}$ & 0.88 & 0.84 & 0.85 \\
\hline & & $75^{\circ}$ & 0.84 & 0.79 & 0.79 \\
\hline
\end{tabular}




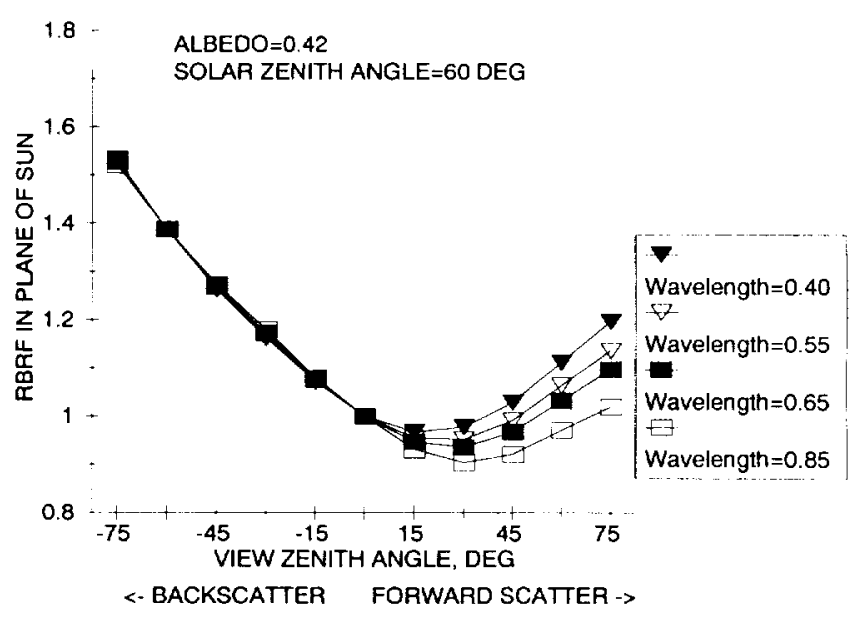

Figure 15. Relative Bidirectional Reflectance Function for albedo of 0.42 and solar-zenith angle of $60^{\circ}$.

1988, Deering et al. (1990) performed similar measurements in a smaller area on the eastern edge of the flats at a location known as Chuck Site. Figure 16 illustrates the location of both areas. The flats at Chuck Site are at a higher altitude $(5$ to $15 \mathrm{~m}$ ) and do not retain moisture as long as the CFTA. Chuck Site soil does not appear to contain as much algae and lichen as the CFTA, but surface texture is similar for both areas. Figure 17 compares RBRF for the two areas for several different albedo values. For the CFTA, it appears that the magnitude of the forward-scattering peak is a strong function of soil moisture as indicated by albedo value. More moist conditions with lower albedos have larger forward-scattering peaks. By coincidence, the Chuck Site albedo taken at the time of the Deering measurements in 1988 is close to the dry CFTA value in 1991. The helicopter CFTA measurements are in close agreement with the Chuck Site data of Deering et al. (1990). Precise agreement is not to be expected because of different measurement techniques and possible small

Figure 16. White Sands/Tularosa Basin (Not to Scale).

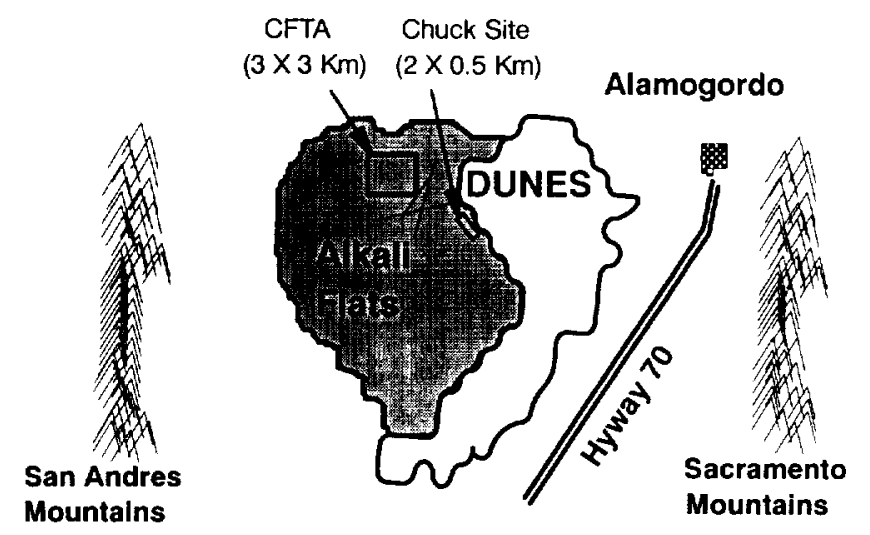

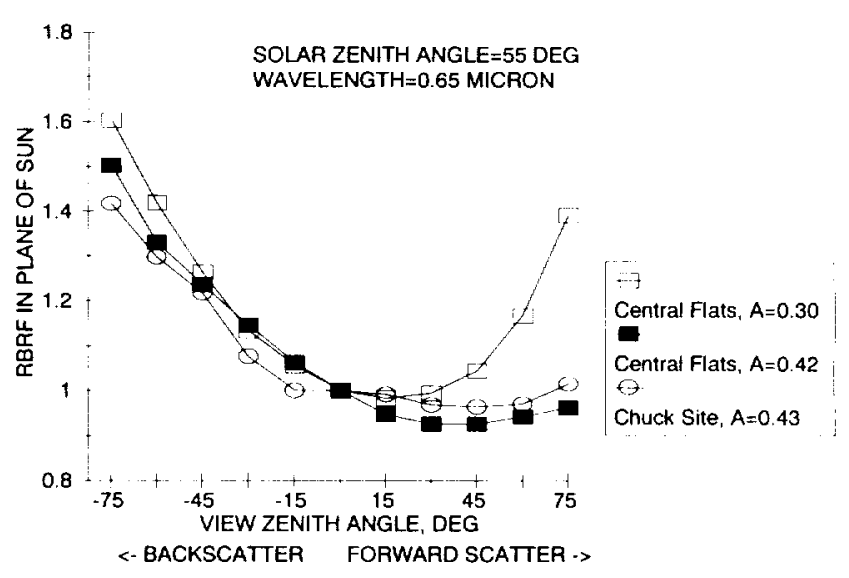

Figure 17. Relative Bidirectional Reflectance Function for two locations on the alkali flats. Albedo values are for wavelength of $0.55 \mu \mathrm{m}$.

differences in surface texture and the amount of thin unstabilized gypsum dust (Wheeler et al., 1994).

\section{CONCLUDING REMARKS}

Soil moisture causes significant change in surface albedo on the alkali flats region of WSMR. Increased wetness causes reduced surface albedo values at all wavelengths. The spectral variation of albedo relative to that at a given wavelength is lightly influenced by moderate changes in soil moisture, however. This suggests that albedo measurements at one wavelength may be used to estimate albedo values at other wavelengths within the interval 0.40 to $0.85 \mu \mathrm{m}$ for a moderate range of soil moisture variation.

The anisotropic factor exhibits minimal spectral variation except in the forward-scattering peak at significant solar-zenith angles. The magnitude of the forward-scattering peak is also sensitive to soil moisture, with wet conditions causing a larger peak.

Comparison of helicopter-derived data with that of Deering et al. (1990) indicates that the two methods give nearly identical results for similar combinations of solar-zenith angle and surface albedo at two different locations on the alkali flats.

Caution is suggested when comparing satellite counts of both the central flats and Chuck Site regions on the same satellite image for large solar-zenith and viewzenith angles. Typically, the central flats region has a lower albedo than Chuck Site because of lower elevation and higher soil moisture. Under such conditions, moisture variation will cause the anisotropic factor to be significantly different for each of the two regions. Satellite radiance differences will no longer be directly proportional to surface albedo differences, as is sometimes assumed. This issue is minimized for low solar-zenith and view-zenith angle conditions. 


\section{REFERENCES}

Barkstrom, B. R. (1976), A finite difference method of solving anisotropic scattering problems, J. Quant. Spectrosc Radiot. Transf. 16:725-739.

Che, N., and Price, J. C. (1992), Survey of radiometric calibration results and methods for visible and near infrared chammels of NOAA-7, -9 , and -11 AVHRRs, Remote Sons. Environ. 41:19-27.

Davis, J. M., and Cox, S. K. (1982), Reflected solar radiances from regional scale scenes, J. Appl Meteor. 21:1698-1712.

Deering, D. W., and Leon, P. (1986), A sphere-scanning radiometer for rapid directional measurements of sky and ground radiance, Remote Sens. Entiron. 19:1-24

Deering, D. W., Eck, T. F., and Otterman, J. (1990), Bidirectional reflectances of selected deserts and their effect on albedo, Agric. Forest Meteor. 52:71-93.

Eaton, F. D., and Dirmhirm, I. (1979), Reflected irradiance indicatrices of natural surfaces and their effect on albedo, Appl. Opt. 18(7):994-1008.

Ellingson, R. G., and Foucuart, Y. (1990), The Intercomparison of Radiation Codes in Climate Models (ICRCCM), WMO/ TD-No. 371, 46 pp. (Available from World Meteorological Organization, (ieneva)

Frouin, R., and Gautier, C. (1987), Calibration of NOAA-7 AVHRR, GOES-5, and GOES-6 VISSR/VAS solar channels, Remote Sens. Enciron. 22:73-101.

Irons, J. R., Ranson, K. J., Willians, D. L., Irish, R. R., and Huegel, F. G. (1991), An off-nadir-pointing imaging spectroradiometer for terrestrial ecosystem studies, IEEF Trans. Geosci. Remote Sens. 29(1):66-74.

Jackson, R. D., Teillet, P. M., Slater, P. N., Fedosejevs, G., Jasinski, M. F., Aase, J. K., and Moran, M. S. (1990), Bidirectional measurements of surface reflectance for view angle corrections of oblique imagery, Remote Sens. Environ. $32: 189-202$.

LeCroy, S. R., Wheeler, R. J., Whitlock, C. H., and Swanson, J. S. (1994), Monitoring desert and Mt. Pinatubo aerosols over the White Sands missile range area, Geophys. Res. Lett., Submitted.

Markham, B. L., Irons, J. R., Deering, D. W., Halthore, R. N., Irish, R. R., Jackson, R. D., Moran, M. S., Bigger, S. F., Gellman, D. I., Grant, B. G., Palmer, J. M., and Slater, P. N. (1990), Radiometric calibration of aircraft and satellite sensors at White Sands, NM, Proc. of the Int. Geosci. and Remote Sens. Symposium (IGARSS' 90). College Park, MD. (Available from IEEE)

Moran, M. S., Jackson, R. D., I Iart, G. F., Slater, P. N., Bartell, R. J., Biggar, S. F., (;ellman, D). I., and Santer, R. P. (1990), Obtaining surface reflectance factors from atmospheric and view angle corrected SPOT-1 HRV data, Remote Sens. Environ. 32:203-214.

Purgold, G. C.., Whitlock, C. H., Wheeler, R. J., and LeCroy, S. R. (1994), A multi-wavelength airborne radiometer scanner (ARS) for measuring surface bidirectional reflectance characteristics, Remote Sens. Environ. 47:322-330.
Rao, C. R. N., and Chen, J. (1993), Calibration of the visible and near-infrared channels of the advanced very high resolution radiometer (AVHRR) after launch. Proc, of the SPIE. Conference on Recent Advances in Sensors, Radiometric Calibration, and Processing of Remotely Sensed Data, Orlando, FL. (Available from SPIE)

Slater, P. N., Biggar, S. F., Holm, R. G., Jackson, R. D., Mao, Y., Moran, M. S., Palmer, J. M., and Yuan, B. (1987). Reflectance- and radiance-based methods for the in-flight absolute calibration of multispectral sensors, Remote Sons. Environ. 22:11-17.

Suttles, J. T. (1981), Anisotropy of Solar Radiation Leaving the Earth-Atmosphere System. Ph.D. Thesis, Old Dominion University, (Available from NTIS, NASA Accession No. N82-32242)

Suttles, J. T. (1985), Radiative Transfer in Scattering and Absorbing Atmospheres (J. I.enoble, Ed.), A. Deepak Publishing, Hampton, VA, pp. 48-50.

Suttles, J. T., Green, R. N., Minnis, P., Smith, G. I., Taylor, W. F., Wielicki, B. A., Walker, I. J., Young, J. F., Taylor, V. R., and Stowe, I. L. (1988), Angular Radiation Models for Earth-Atmosphere System, Volume 1 - Shortwace Radiation, NASA Reference Publication 1184.

Walraven, R. L., and Coulson, K. L. (1972), Measurements of the light properties of gypsum sand, Contrib. Atmos. Sci. 7 , $140 \mathrm{pp}$.

Wheeler, R. W., LeCroy, S. R., Whitlock, C. H., Purgold, G. C., and Swanson, J. S. (1994), Surface characteristics for the alkali flats and dunes regions at White Sands missile range, NM, Remote Sens. Environ., 48:181-190.

Whitlock, C. H., Purgold, G. C., and LeCroy, S. R. (1987), Surface Bidirectional Reflectance Properties of Two Southwestern Arizona Deserts for Wavelengths Between 0.4 and 2.2 Micrometers. NASA TP 2643. (Available from NTIS.)

Whitlock, C. H., Staylor, W. F., Suttles, J. T., Smith, G., Levin, R., Frouin, R, Gautier, C., Teillet, P. M., Slater, P. N., Kaufman, Y. J., Holben, B. N., Rossow, W. B., Brest, C., and LeCroy, S. R. (1990), AVHRR and VISSR Satellite Instrument Calibration Results for Both Cirrus and Marine Stratocumulus IFO Periods, Fire Science Report 1988. NASA CP 3083, pp. 141-145. (Available from NTIS.)

Whitlock, C. H., Suttles, J. T., Sebacher, D. I., Fuller, W. H., and LeCroy, S. R. (1985), Interpretation of spectral radiation experiments using finite-difference radiative transfer theory. IRS84: Current Problems in Atmospheric Radiation (G. Fiocco, Ed.), A. Deepak Publishing, Hampton, VA, pp. 293-296.

Williams, D. L., Walthall, C. L., and Young, D. (1991), A Pointable Helicopter-Based Remote Sensing Data Accuisition System for Collecting Bidirectional Reflectance Data, Proceedings of the Fourth Airborne Geosci. Workshop, La Jolla, CA. (Available from NTIS, NASA Accession No. N9125491) 
